\title{
BMJ Open Microvascular Outcomes after Metabolic Surgery (MOMS) in patients with type 2 diabetes mellitus and class I obesity: rationale and design for a randomised controlled trial
}

\author{
Ricardo Vitor Cohen, ${ }^{1}$ Tiago Veiga Pereira, ${ }^{2}$ Cristina Mamédio Aboud, ${ }^{3}$ \\ Pedro Paulo de Paris Caravatto, ${ }^{1}$ Tarissa Beatrice Zanata Petry, ${ }^{1}$ \\ José Luis Lopes Correa, ${ }^{1}$ Carlos Aurélio Schiavon, ${ }^{4}$ Mariangela Correa, ${ }^{3}$ \\ Carlos Eduardo Pompílio, ${ }^{1}$ Fernando Nogueira Quirino Pechy, ${ }^{1}$ Carel le Roux, ${ }^{5}$ \\ on behalf of MOMS Study Investigators
}

To cite: Cohen RV, Pereira TV, Aboud CM, et al. Microvascular Outcomes after Metabolic Surgery (MOMS) in patients with type 2 diabetes mellitus and class I obesity: rationale and design for a randomised controlled trial. BMJ Open 2017;7: e013574. doi:10.1136/ bmjopen-2016-013574

- Prepublication history for this paper is available online. To view these files please visit the journal online (http://dx.doi.org/10.1136/ bmjopen-2016-013574).

Received 21 July 2016 Revised 22 September 2016 Accepted 15 November 2016

CrossMark

For numbered affiliations see end of article.

Correspondence to Dr Ricardo Vitor Cohen; ricardo.cohen@haoc.com.br

\section{ABSTRACT}

Introduction: There are several randomised controlled trials (RCTs) that have already shown that metabolic/ bariatric surgery achieves short-term and long-term glycaemic control while there are no level $1 \mathrm{~A}$ of evidence data regarding the effects of surgery on the microvascular complications of type 2 diabetes mellitus (T2DM).

Purpose: The aim of this trial is to investigate the long-term efficacy and safety of the Roux-en-Y gastric bypass (RYGB) plus the best medical treatment (BMT) versus the BMT alone to improve microvascular outcomes in patients with T2DM with a body mass index (BMI) of $30-34.9 \mathrm{~kg} / \mathrm{m}^{2}$.

Methods and analysis: This study design includes a unicentric randomised unblinded controlled trial. 100 patients (BMI from 30 to $34.9 \mathrm{~kg} / \mathrm{m}^{2}$ ) will be randomly allocated to receive either RYGB plus BMT or BMT alone. The primary outcome is the change in the urine albumin-to-creatinine ratio (UACR) captured as the proportion of patients who achieved nephropathy remission (uACR $<30 \mathrm{mg} / \mathrm{g}$ of albumin/mg of creatinine) in an isolated urine sample over 12, 24 and 60 months.

Ethics and dissemination: The study was approved by the local Institutional Review Board. This study represents the first RCT comparing RYGB plus BMT versus BMT alone for patients with T2DM with a BMI below $35 \mathrm{~kg} / \mathrm{m}^{2}$.

Trial registration number: NCT01821508;

Pre-results.

\section{INTRODUCTION}

Type 2 diabetes mellitus (T2DM) is one of the leading causes of morbidity and mortality worldwide. Six randomised controlled trials (RCTs) have shown that short-term and

\section{Strengths and limitations of this study}

This is a randomised controlled trial designed to compare the effects of Roux-en-Y gastric bypass (RYGB) plus best medical treatment (BMT) and BMT alone on patients with type 2 diabetes mellitus (T2DM) with microvascular complications and with body mass index (BMI) from 30 to $35 \mathrm{~kg} / \mathrm{m}^{2}$, the most prevalent BMI range of T2DM.

- The long-term follow-up will allow to assess the durability of the metabolic effect after RYGB, an issue never tested in this BMI population.

- The study was designed to be performed using optimised methodological resources in order to prevent systematic bias.

- The study cannot be blinded as one of the interventions is RYGB.

- The level of physical activity was not measured in a systematic manner in study participants.

long-term glycaemic control after metabolic surgery is superior to the best medical care without surgery. ${ }^{1-7}$ Metabolic surgery additionally improves dyslipidaemia, inflammation and blood pressure. ${ }^{8-10}$ Mortality was also reduced after surgery, especially in those patients with $\mathrm{T} 2 \mathrm{DM},{ }^{11-15}$ although baseline body mass index (BMI) did not predict benefit; rather, non-anthropometric parameters such as fasting insulin did predict cardiovascular events and mortality. ${ }^{16-21}$

The risk of developing microvascular complications depends on both the duration and severity of hyperglycaemia and the other components of metabolic syndrome, ${ }^{22}$ and for any treatment modality to be successful, 
more than glycaemia needs to be addressed. ${ }^{23} 24$ The subgroup of patients with diabetes and chronic kidney disease (CKD), regardless of their BMI, as manifested by albuminuria, impaired glomerular filtration rate or both have the highest mortality, while it also is the leading cause for renal replacement therapy. ${ }^{25} 26$ Those without CKD have a much lower risk of morbidity and mortality. In spite of the importance to avoid or treat microvascular T2DM complications, the vast majority of metabolic surgery studies have focused on glycaemic control, while insufficient attention has been directed to complications of T2DM. ${ }^{27-30}$

The main legacy of this study is to provide data supporting that metabolic surgery associated with the best medical treatment (BMT) might be superior to the BMT alone to treat microvascular complications in the BMI range where T2DM is more prevalent.

\section{Objectives}

The aim of this trial is to investigate the long-term efficacy and safety of the Roux-en-Y gastric bypass (RYGB) plus the BMT versus the BMT alone to improve microvascular outcomes in patients with T2DM with a BMI of $30-34.9 \mathrm{~kg} / \mathrm{m}^{2}$.

\section{Trial design}

Microvascular Outcomes after Metabolic Surgery (MOMS) is a randomised, two-arm (with allocation ratio 1:1), controlled, single-centre phase III clinical trial (figure 1). The primary end point is the change in the urine albumin:creatinine ratio (uACR) captured as the proportion of patients who achieved nephropathy remission (uACR $<30 \mathrm{mg} / \mathrm{g}$ of albumin $/ \mathrm{mg}$ of creatinine) in an isolated urine sample (morning) over 12, 24 and 60 months. Patient recruitment occurred from April 2013 to March 2016. All surgical procedures were completed by April 2016. The trial was prospectively registered in ClinicalTrials.gov (NCT01821508). Intermediate (preliminary) analyses will also be performed at prespecified follow-up periods of 12 and 24 months. The last patient final visit is scheduled for April 2021 (60 months' follow-up).

The study centre developed some strategies to guarantee the quality and completeness of data and procedures (use of checklists and workflow). An independent professional will enter study acquired information on a webbased data entry system (Medscale). This method was parameterised to generate automatic queries and to maximise the collection of consistent and valid data. A monitor (dedicated and designed specifically for this protocol) will audit the overall quality and completeness of the data entered on the electronic case report form (eCRF), examine source documents, compliance of all study team with Good Clinical Practice, the integrity of the regulatory binder and communication with the Institutional Review Board (IRB).

\section{METHODS}

\section{Study setting}

The study is conducted in a diabetes and obesity care centre affiliated with a 400-bed private tertiary care hospital in São Paulo, Brazil.
Figure 1 Simplified MOMS algorithm. BMT, best medical treatment; HbA1c, glycated haemoglobin; MOMS, Microvascular Outcomes after Metabolic Surgery; RYGB, Roux-en-Y gastric bypass.

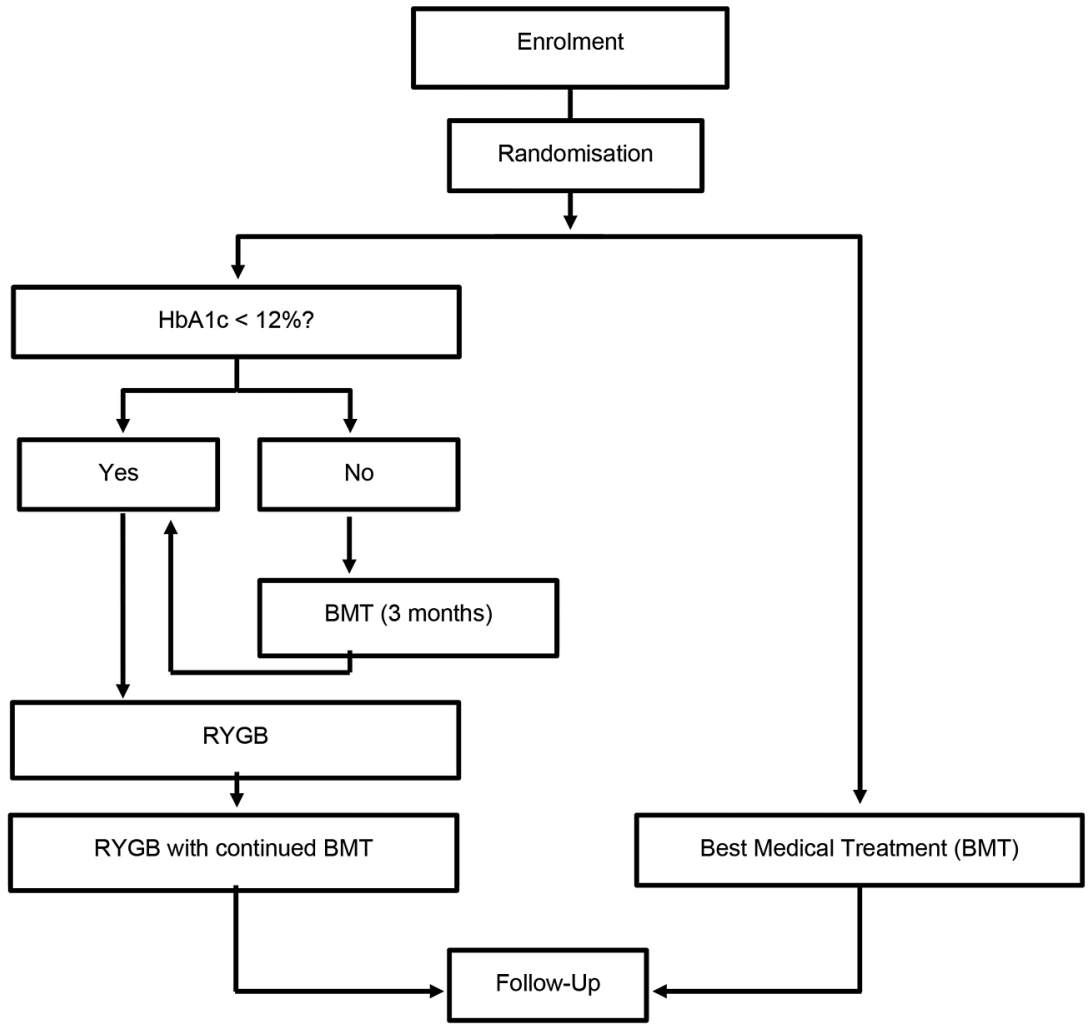




\section{Eligibility criteria}

Inclusion criteria

Patients with diabetic kidney disease as defined by albuminuria and an estimated glomerular filtration rate $>30 \mathrm{~mL} / \mathrm{min}$ treated within a specialist diabetes service had to comply with all of the following criteria at randomisation:

1. Age: $18-65$ years;

2. BMI: $30-34.9 \mathrm{~kg} / \mathrm{m}^{2}$;

3. <15 years of history of T2DM;

4. Negative glutamic acid decarboxylase autoantibodies test;

5. Fasting $\mathrm{C}$ peptide over $1 \mathrm{ng} / \mathrm{mL}$;

6. Appropriate postprandial $\mathrm{C}$ peptide response after a $500 \mathrm{kcal}$ mixed meal challenge.

\section{Exclusion criteria}

1. Autoimmune diabetes or type 1 diabetes;

2. Previous abdominal operations that would complicate an RYGB;

3. Pregnancy or women of childbearing age without an effective contraceptive;

4. Alcoholism or illicit drug use;

5. Severe hepatic disease that may complicate RYGB;

6. Inflammatory bowel disease or malabsorptive syndrome;

7. Major cardiovascular event in the past 6 months;

8. Current angina;

9. Severe psychiatric disorders that would complicate follow-up after RYGB;

10. Use of immunosuppressive drugs, chemotherapy and/or radiotherapy;

11. Uncontrolled coagulopathy;

12. Advanced proliferative retinopathy with or without amaurosis;

13. CKD stage 4 or 5 waiting for renal replacement therapy;

14. Stage 3 peripheral neuropathy;

15. Pulmonary embolism in the past 2 years.

\section{Interventions}

After randomisation, patients were allocated in a 1:1 ratio to RYGB plus BMT or BMT only (figure 2).

\section{Best medical treatment}

'BMT' is defined as the use of current best clinical treatment available (table 1). T2DM medication titration was and will be performed by the investigators and will be based on home-checked glycaemia and blood test results ordered during follow-up visits.

\section{RYGB plus BMT}

Patients allocated to RYGB will receive a similar BMT compared with the control group. All operations were completed by a single experienced surgeon and the last procedure was performed in early April 2016. On the day before the procedure, patients received a liquid diet, continued their medication, except if otherwise suggested by the attending investigator. Patients were admitted to the hospital 12 hours before the operation and started fasting 8-10 hours before surgery. After admission, patients underwent a preanaesthetic visit.

Laparoscopic RYGB was performed under general anaesthesia and consisted of the creation of the gastric pouch $(20-30 \mathrm{~mL})$, a biliary limb of $80 \mathrm{~cm}$ and alimentary limb of $150 \mathrm{~cm}$, with a side-to-side jejunojejunostomy and a linear stapler gastrojejunostomy (figure 3). Concomitant cholecystectomy was performed in patients with preoperative cholelithiasis. Deep vein thrombosis prophylaxis included compression stockings and intermittent pneumatic compressors. Cefazolin $2 \mathrm{~g}$ was administered during anaesthesia induction and 8 hours after the end of the operation. The surgical arm received and will keep receiving during follow-up the same amount of nutritional counselling and included information on food consistency and progression to solids. All medications are managed by the endocrinology team. First, insulin will be titrated and may be withdrawn, followed by liraglutide, linagliptin and empagliflozin. Metformin will be maintained throughout the trial. The parameters of full medication withdrawal in the RYGB+BMT are fasting glucose below $100 \mathrm{mg} / \mathrm{dL}$ and glycated haemoglobin $(\mathrm{HbA} 1 \mathrm{c})<6.0 \%$. ACE inhibitor and angiotensin II receptor blockers are continued in all groups, even in patients with negative albuminuria. Simvastatin is also prescribed and maintained.

\section{Drug titration}

Drugs with a beneficial effect on microvascular and macrovascular will be continued even if uACRs normalise. Antidiabetic medications, including insulin, may have their dose reduced to avoid hypoglycaemia. Metformin will be continued in all cases, but the doses may be reduced if $\mathrm{HbAlc}$ was below $5.7 \%$ and fasting plasma glucose (FPG) below $100 \mathrm{mg} / \mathrm{dL}$. On the basis of our previous experience in metabolic surgery in patients with T2DM who have BMI $<35 \mathrm{~kg} / \mathrm{m}^{2}$ (30) after 8-10 years of follow-up, we can associate less T2DM recurrence when metformin is not discontinued (unpublished data). The insulin sensitiser drug may have its dose decreased when HbA1c is lower than 5.7\% and even discontinued if hypoglycaemia is detected.

\section{Concomitant care: nutritional evaluation and physical activity}

As part of a multidisciplinary team approach, all patients will be advised by a dietitian to reduce food intake and to increase physical activity. Patients also completed 24 hours daily dietary intake.

\section{Concomitant care: management of other comorbidities}

All other conditions such as hypertension and hyperlipidaemia are evaluated and treated according to standard recommendations and guidelines. Compliance is also registered during follow-up visits. 


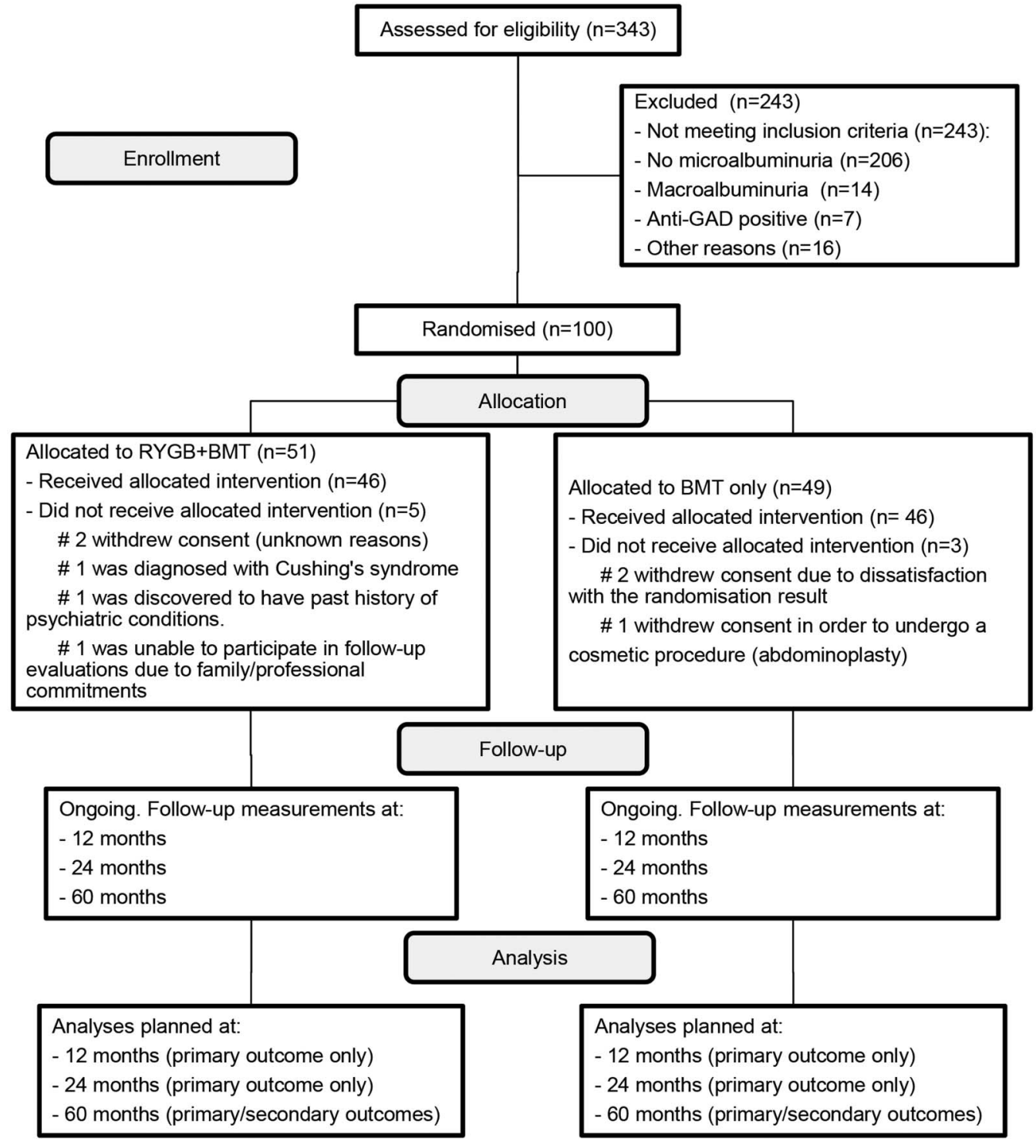

Figure 2 CONSORT 2010 standard RCT flow diagram for MOMS trial. BMT, best medical treatment; CONSORT, Consolidated Standards of Reporting Trials; GAD, glutamic acid decarboxylase; RYGB, Roux-en-Y gastric bypass.

\section{Outcomes}

\section{Primary outcome}

The main outcome is the change in the uACR (intention-to-treat (ITT) analysis) captured as the proportion of patients who achieved nephropathy remission (uACR $<30 \mathrm{mg} / \mathrm{g}$ of albumin $/ \mathrm{mg}$ of creatinine) in an isolated urine sample (morning) over 12, 24 and 60 months.

\section{Secondary outcomes}

The secondary outcomes are changes in diabetic retinopathy, changes in diabetic neuropathy, use of antidiabetic medication, glycaemic control (defined as FPG $<100 \mathrm{mg} / \mathrm{dL}$ and HbA1c $<6.0 \%$ with or without medication), blood pressure control (defined as systolic blood pressure $<130 \mathrm{~mm} \mathrm{Hg}$ and diastolic $<80 \mathrm{~mm} \mathrm{Hg}$ ), lipid control (defined as low-density lipoprotein $<100$ and $<70 \mathrm{mg} / \mathrm{dL}$ in patients with previous cardiovascular events; high-density lipoprotein $>50 \mathrm{mg} / \mathrm{dL}$ and triglycerides $<150 \mathrm{mg} / \mathrm{dL}$, hepatic fibrosis assessed through intraoperative liver biopsy and control evaluated by postoperative liver elastography, fatal and non-fatal cardiovascular events, quality of life (36-item Short Form Health Survey, SF-36) and diabetic urinary bladder dysfunction (assessed through a questionnaire).

\section{Participant timeline \\ Screening visit}

The screening visit was performed by one of the medical investigators with the help of a research nurse. Information about the study design, procedures, follow-up visits and all risks involved in both arms of the trial was explained. Then a checklist containing the inclusion and exclusion criteria was completed. All patients provided written informed consent previously to all study procedures. Those patients not using optimal 
Table 1 List of medications prescribed in both groups

\begin{tabular}{|c|c|c|c|}
\hline T2DM medication & ARBs/ACE inhibitors & Statins & Others \\
\hline $\begin{array}{l}\text { Metformin } 2 \mathrm{~g} / \text { day } \\
\text { Pioglitazone } 30 \mathrm{mg} \\
\text { Linagliptine } 5 \mathrm{mg} \\
\text { Liraglutide } 1.8 \mathrm{mg} \text { od } \\
\text { Glargine insulin } \\
\text { Glulisine insulin } \\
\text { Empaglifozin } 10 \mathrm{mg}\end{array}$ & $\begin{array}{l}\text { Losartan } 25 \mathrm{mg} \\
\text { Enalapril } 5 \mathrm{mg}\end{array}$ & Simvastatin $20 \mathrm{mg}$ & $\begin{array}{l}\text { Thioctic acid } 600 \mathrm{mg} \\
\text { Antihypertensive agents } \\
\mathrm{Na}+\text { proton pump inhibitors }\end{array}$ \\
\hline
\end{tabular}

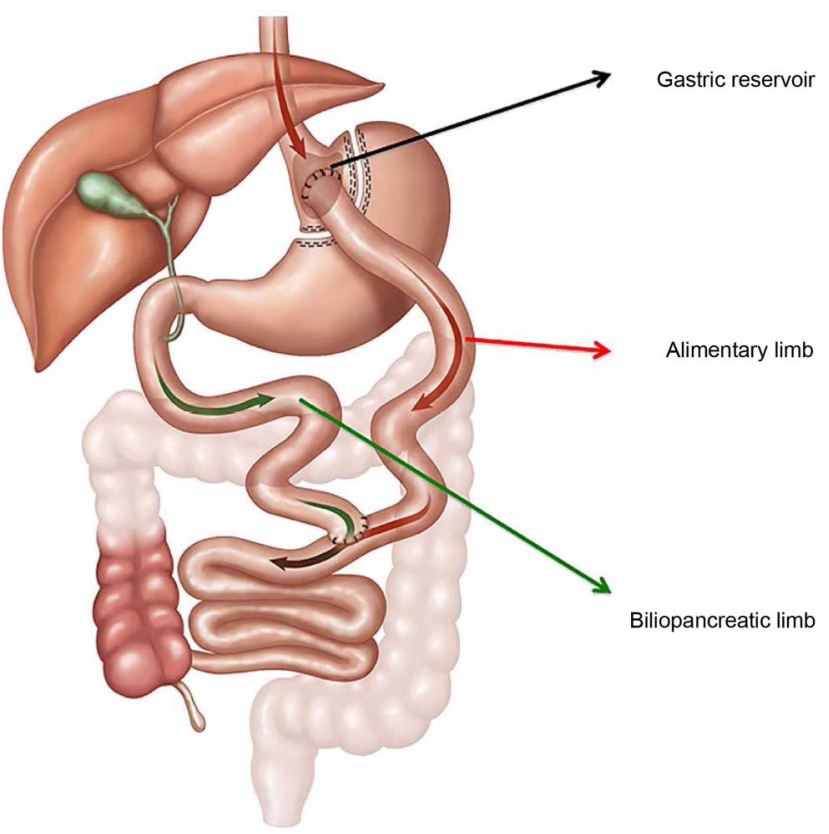

Figure 3 Laparoscopic RYGB. RYGB, Roux-en-Y gastric bypass.

drugs for glycaemic control, blood pressure or dyslipidaemia were started on the appropriate medication. All eligible patients had coloured retinography, angiofluoresceinography and eye refraction examinations. Baseline blood and imaging tests (echocardiogram, X-ray, abdominal ultrasound and ECG) were ordered.

\section{Randomisation visit}

A comprehensive clinical evaluation was undertaken to confirm eligibility 4-6 weeks after screening. After eligibility confirmation, patients received an identification number that was used in all documentation. During this visit, an assessment to evaluate neuropathy was performed through vibratory and pinprick sensation tests.

Patients randomised to the RYGB+BMT arm were further assessed with upper digestive endoscopy and elastography ultrasound. Two weeks after the randomisation visit, all the tests were reviewed to ensure that all patients were eligible to proceed. Both groups were seen by a dietitian who also took anthropometric measurements. The dietitian reinforced the benefits of intense lifestyle modifications.

\section{Follow-up}

Patients in the RYGB+BMT arm were seen after 1 and 4 weeks from the index procedure by the medical investigators and the dietitian. All adverse events (AEs) were captured. Changes were made to diet, physical activity and medications as appropriate to optimise T2DM control. After the first month, patients from both arms had and will have their follow-up consultations at the same intervals. A physical examination will be performed on all visits and samples will be collected until the end of the study (table 2).

\section{Sample size}

The study was designed to show a difference in the proportion of participants achieving a healthy uACR (remission) at the time point of 60 months (primary end point defined a binary outcome). The proportion of patients expected to achieve remission was sourced from previous publications, ${ }^{30} 31$ empirical data from a surgeon (RVC) with extensive experience in bariatric surgery as well as a consensus and expert opinion of a panel of seven specialists in obesity/diabetes (RC, ClR, PPdPC, TBZP, JLLC, CAS, FNQP).

Remission was estimated to occur in $50 \%$ of participants in the RYGB+BMT arm and $10 \%$ of participants in the BMT-only arm. To accommodate two prespecified (preliminary) analyses at follow-up times of 12 and 24 months, the significance level was set at the $1.7 \% \alpha$ level for the primary outcome (Bonferroni adjustment). Thus, to detect the expected difference in the proportion of participants achieving remission and anticipating a potential 5-year $20 \%$ loss of follow-up rate, a sample size of 100 patients (50 participants in each group) will give a $\geq 90 \%$ statistical power at an $\alpha$ level of $1.7 \%$.

\section{Recruitment strategy}

Advertisements

Recruitment started in April 2013. Initially, candidates were referred from several private and public healthcare providers from the city of Sao Paulo, Brazil. Then a press release with an overview of the trial, goals and eligibility criteria was published in a major Brazilian 


\begin{tabular}{|c|c|c|c|c|c|c|c|c|c|c|c|c|c|c|c|c|c|c|c|c|c|c|c|}
\hline \multirow[b]{2}{*}{ Assessments } & \multicolumn{10}{|l|}{ Year 1} & \multicolumn{4}{|c|}{ Year 2} & \multicolumn{3}{|c|}{ Year 3} & \multicolumn{3}{|c|}{ Year 4} & \multicolumn{3}{|c|}{ Year 5} \\
\hline & Screen & Random & Surgery ${ }^{\star}$ & $\begin{array}{l}\text { First until third } \\
\text { PO }\end{array}$ & $\begin{array}{l}W \\
1\end{array}$ & $\begin{array}{l}W \\
4\end{array}$ & $\begin{array}{l}M \\
3\end{array}$ & $\begin{array}{l}M \\
6\end{array}$ & $\begin{array}{l}M \\
9\end{array}$ & $\begin{array}{l}M \\
12\end{array}$ & $\begin{array}{l}M \\
15\end{array}$ & $\begin{array}{l}M \\
18\end{array}$ & $\begin{array}{l}M \\
21\end{array}$ & $\begin{array}{l}M \\
24\end{array}$ & $\begin{array}{l}M \\
28\end{array}$ & $\begin{array}{l}M \\
32\end{array}$ & $\begin{array}{l}M \\
36\end{array}$ & $\begin{array}{l}\mathrm{M} \\
40\end{array}$ & $\begin{array}{l}M \\
44\end{array}$ & $\begin{array}{l}M \\
48\end{array}$ & $\begin{array}{l}M \\
52\end{array}$ & $\begin{array}{l}M \\
56\end{array}$ & $\begin{array}{l}M \\
60\end{array}$ \\
\hline Informed consent & $x$ & & & & & & & & & & & & & & & & & & & & & & \\
\hline Medical history & $x$ & & & & & & & & & & & & & & & & & & & & & & \\
\hline Physical examination & $x$ & & & & & & & $x$ & & $x$ & & $x$ & & $x$ & $x$ & $x$ & $x$ & $X$ & $x$ & $x$ & $x$ & $x$ & $x$ \\
\hline Medical assessment & $x$ & $x$ & $x$ & $x$ & $X^{*}$ & $x$ & $x$ & $x$ & $x$ & $x$ & $x$ & $x$ & $x$ & $x$ & $x$ & $x$ & $x$ & $x$ & $x$ & $x$ & $\mathrm{X}$ & $x$ & $x$ \\
\hline Concomitant medication & $x$ & $x$ & & $x$ & $x$ & $x$ & $x$ & $x$ & $x$ & $x$ & $x$ & $x$ & $x$ & $x$ & $x$ & $x$ & $x$ & $x$ & $x$ & $x$ & $x$ & $x$ & $x$ \\
\hline Inclusion/exclusion criteria & $x$ & $x$ & & & & & & & & & & & & & & & & & & & & & \\
\hline Randomisation & & $x$ & & & & & & & & & & & & & & & & & & & & & \\
\hline Adverse events & & $x$ & $x$ & $x$ & $x$ & $x$ & $x$ & $x$ & $x$ & $x$ & $x$ & $x$ & $x$ & $x$ & $x$ & $x$ & $x$ & $x$ & $x$ & $x$ & $x$ & $x$ & $x$ \\
\hline Nerve conduction studies & $x$ & & & & & & & $x$ & & $x$ & & $x$ & & $x$ & $x$ & $x$ & $x$ & $\mathrm{X}$ & $x$ & $x$ & $x$ & $x$ & $x$ \\
\hline Nutritional assessment & & $x$ & & & $x$ & $x$ & $x$ & $x$ & $x$ & $x$ & $x$ & $x$ & $x$ & $x$ & $x$ & & $x$ & $x$ & & $x$ & $x$ & & $x$ \\
\hline SF-36, IPSS and OAB-Qsf & $x$ & & & & & & & & & $x$ & & & & $x$ & & & $x$ & & & $x$ & & & $x$ \\
\hline Urinary diary & $x$ & & & & & & $x$ & $x$ & & $x$ & & & & $x$ & & & $x$ & & & $x$ & & & $x$ \\
\hline Serum pregnancy test & $x$ & & & & & & & & & & & & & & & & & & & & & & \\
\hline CBC & $x$ & & & & & & & & & $x$ & & $x$ & & $x$ & & & $x$ & & & $x$ & & & $x$ \\
\hline AST/ALT & $x$ & & & & & & & & & $x$ & & & & $x$ & & & $x$ & & & $x$ & & & $x$ \\
\hline Amylase & $x$ & & & & & & & $x+$ & & & & $x+$ & & & $x$ & & & $x$ & & & $x$ & & \\
\hline Sodium and potassium & $x$ & & & & & & & & & & & & & & & & & & & & & & \\
\hline Urea and creatinine & $x$ & & & & & & $x$ & $x$ & & $x$ & & $x$ & & $x$ & $x$ & $x$ & $x$ & $x$ & $x$ & $x$ & $x$ & $x$ & $x$ \\
\hline PT and aPPT & $x$ & & & & & & & & & & & & & & & & & & & & & & \\
\hline Lipids & $x$ & & & & & & & $x$ & & $x$ & & $x$ & & $x$ & $x$ & & $x$ & $x$ & & $x$ & $x$ & & $x$ \\
\hline Fasting plasma glucose & & & & $x$ & $X^{*}$ & $x$ & $x$ & & $x$ & & $x$ & & $x$ & & $x$ & $x$ & $x$ & $x$ & $x$ & $x$ & $x$ & $x$ & $x$ \\
\hline $\mathrm{HbA} 1 \mathrm{c}$ & $x$ & & & & & & $x$ & $x$ & $x$ & $x$ & $x$ & $x$ & $x$ & $x$ & $x$ & $x$ & $x$ & $x$ & $x$ & $x$ & $x$ & $x$ & $x$ \\
\hline $\begin{array}{l}\text { Microalbumin and } \\
\text { creatinine }\end{array}$ & $x$ & & & & & & & $x$ & & $x$ & & $x$ & & $x$ & $x$ & & $x$ & $x$ & & $x$ & $x$ & & $x$ \\
\hline Iron and ferritin & $x$ & & & & & & & $x$ & & $x$ & & & & $x$ & & & $x$ & & & $x$ & & & $x$ \\
\hline $\begin{array}{l}\text { Calcium, PTH and vitamin } \\
\text { D }\end{array}$ & $x$ & & & & & & & $x$ & & $x$ & & $x$ & & $x$ & & & $x$ & & & $x$ & & & $x$ \\
\hline Folic acid & $x$ & & & & & & & $x$ & & & & & & $x$ & & & $x$ & & & $x$ & & & $x$ \\
\hline Vitamin $A, B_{1}$ and $B_{12}$ & $x$ & & & & & & & $x$ & & & & $\mathrm{X}$ & & $x$ & & & $x$ & & & $x$ & & & $X$ \\
\hline Anti-GAD & $\mathrm{X}$ & & & & & & & & & & & & & & & & & & & & & & \\
\hline PSA & $x$ & & & & & & & & & & & & & & & & & & & & & & \\
\hline PCR & & & $x$ & & & & $X^{*}$ & $X^{*}$ & & $X^{*}$ & & $X^{*}$ & & $X^{*}$ & $X^{*}$ & & $X^{*}$ & $X^{*}$ & & $X^{*}$ & $X^{*}$ & & $X^{*}$ \\
\hline HIV test & $x$ & & & & & & & & & & & & & & & & & & & & & & \\
\hline MMTT & $x$ & & & & & & & $x$ & & $x$ & & $x$ & & $x$ & $x$ & & $x$ & $X$ & & $x$ & $x$ & & $x$ \\
\hline Urine sample (DNA) & & $x$ & & & & & & $x$ & & $x$ & & & & $x$ & & & $x$ & & & $x$ & & & $x$ \\
\hline Urinalysis & $x$ & & & & & & & & & $x$ & & & & $x$ & & & $X^{*}$ & & & $x$ & & & $x$ \\
\hline Chest X-ray & $x$ & & & & & & & & & & & & & & & & & & & & & & \\
\hline Abdominal ultrasound & $x$ & & & & & & & & & & & & & & & & & & & & & & \\
\hline ECG & $x$ & & & & & & & & & & & & & & & & & & & & & & \\
\hline Echocardiogram & $\mathrm{X}$ & & & & & & & & & & & & & & & & & & & & & & $x$ \\
\hline
\end{tabular}




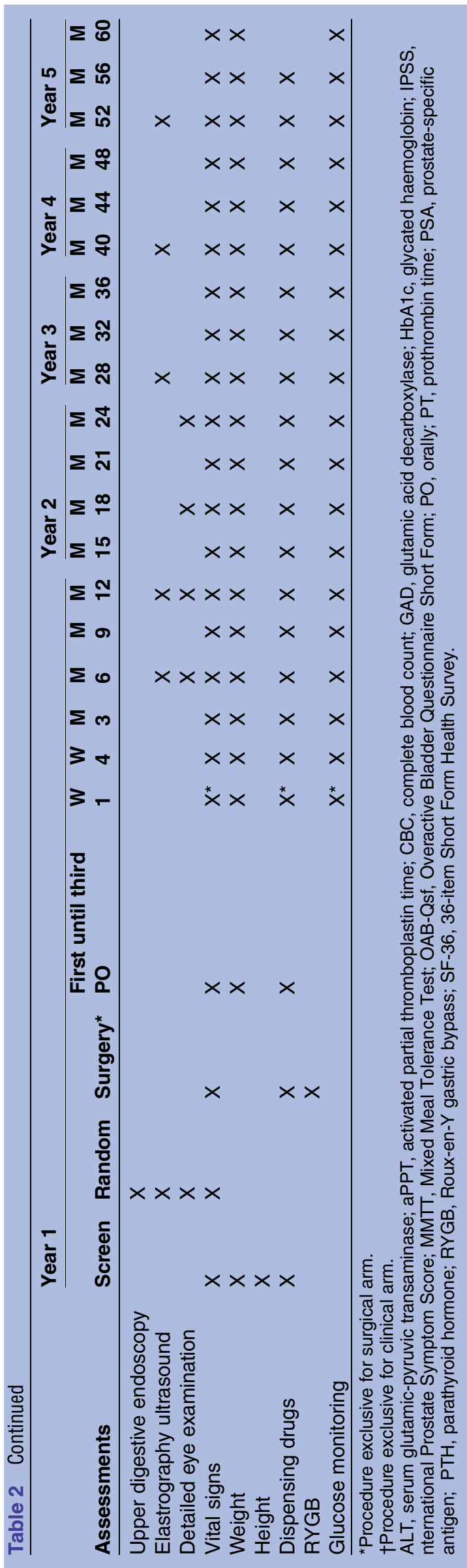

newspaper and disseminated through major online news websites. Finally, several posts were published in social media applications.

After reaching a dedicated trial 'hotsite', the candidates completed an online form with general information on their BMI, time of diagnosis of T2DM and history of microvascular complications. The information was sent to a dedicated hospital's email address. Eligible candidates were invited to a screening visit at the Oswaldo Cruz German Hospital Health Research Unit where written informed consent was obtained.

\section{Assignment of interventions \\ Sequence generation}

Randomisation was carried out by an independent investigator not involved in patient enrolment, treatment or follow-up (central randomisation). Computer-generated random numbers (Stata V.14.0, StataCorp, College Station, Texas, USA) were used to assign randomly, in a 1:1 ratio, patients either to RYGB+BMT or BMT only using a permuted stratified block randomisation procedure with random block sizes of 2, 4 and 6. Randomisation was stratified by gender and block sizes were kept confidential to avoid prediction of future patients' allocation.

\section{Concealment mechanism}

Randomisation codes were released only after patients had been formally recruited into the trial. The randomisation sequence was prepared in advance by the study biostatistician and was concealed from all research investigators at all times. Participants, staff members and researchers could not foresee assignment because of central allocation. All patients who gave consent for participation were pseudoanonymised (personal information was removed and replaced with a coded identifier), and this list was supplied to the central allocation, which randomly allocated patients into the BMT+RYGB arm or BMT-only arm.

\section{Blinding}

Blinding was not possible because of the nature of the intervention. However, investigators in charge of the statistical analysis and laboratory personnel will be blinded to the allocation status of each participant in the trial.

\section{Data management}

Several procedures are performed to assure data quality, including missing data, permitted/non-permitted value ranges and logic checks. To get high-quality data and keep the number of errors and missing data as little as possible, several checklists and standard operational procedures were created and adopted to ensure that data were complete and reliable. The training and consistency of process were straightforward since this is a single-centre study. The study team was trained before the beginning of the study and received an individual delegation from the principal investigator, according to 
his professional expertise. Each participant received a numerical code to ensure his confidentiality and tracking. Source documents (paper) and original study forms have been kept at the site (in a secure and accessible place). Storage follows the numerical code while the access is limited to the study team.

A case report form was designed, and an eCRF was created (Medscale). The site study team is responsible for eCRF entry data. Each study staff member received training and a login/password to access eCRF, and the type of activity that may be undertaken is regulated by the privileges associated with each login. The Medscale eCRF system was parametrised to perform data validation and discrepancy management.

A dedicated monitor (dedicated and designed specifically for this protocol) is responsible for source data verification and the creation of queries and/or data clarification forms for all participants' source documents. Quality assurance and control will be assured by this dedicated monitor, and a statistician will be responsible for final data validation and database analysis throughout the duration of the study.

\section{Retention}

We anticipated a 15-20\% 5-year loss to follow-up rate and planned our sample size accordingly. However, after randomisation, trial coordinators will make every doable effort to follow participants for the entire trial period. Strategies involving actual contact (phone calls, emails and standard mail) will be developed and implemented to achieve the highest possible level of follow-up.

\section{Participant withdrawals}

Individuals who decide to withdraw from the trial will be asked to provide continued monitoring and further data collection after their withdrawal. Participants who were lost to follow-up despite several attempts to reach them will have their data imputed.

\section{Statistical methods}

All analyses will be based on the ITT principle. An overview of methods of analysis is presented in table 3 . We will compare the proportion of participants achieving the primary outcome between RYGB+BMT versus BMT groups using an unconditional logistic regression model. We will also investigate both the occurrence and timing of albumin:creatinine ratio normalisation throughout the 5-year follow-up period by using a Cox proportional hazards model. The proportional hazards assumption will be confirmed by testing the interaction with $\log$ (time) as well as graphically via plots of Schoenfeld residuals. Both in the logistic and Cox proportional hazard models, we will include as covariates baseline albumin: creatinine ratio, BMI, age, diabetes medication use, glucose and HbAlc levels as well as the duration of T2DM. Continuous outcomes will be analysed by mixed-effects generalised linear models adjusting for the baseline version of the response variable. Missing data will be handled using multiple imputation methods assuming that data are missing at random. Demographic and clinical characteristics of participants will be compared between groups (RYGB+BMT vs BMT) using the unpaired Student's t-test for continuous variables, whereas dichotomous variables will be tested using Fisher's exact test and its generalisations for 2xk tables (when necessary). Data will be expressed as mean $\pm \mathrm{SD}$, median (IQR) or counts (percentage) when appropriate. Whenever feasible, variables with asymmetric distributions will be transformed using standard mathematical functions (eg, logarithm, square root, etc). Statistical significance will be set at the $1.7 \%$ level (two-sided) for the primary outcome and 5\% for secondary outcomes. Main conclusions will be based on the ITT principle and on the logistic regression model. All data analyses will be performed using the Stata package (V.13.0, Stata Corp, College Station, Texas, USA).

\section{Additional analyses}

Primary analyses will be carried out on an ITT basis, but subsequent studies may be conducted on a per protocol basis. Primary analyses will also be performed with multiple imputation methods. However, we will also provide results from analyses restricted to complete cases, for comparison with results from the multiple imputation processes.

\section{Adjusted analysis}

All statistical models will be run with appropriate adjustment for baseline characteristics.

\section{Analysis population and missing data}

In the case of missing data, we will perform and report the multiple imputation analysis according to the recommendations of White et $a l^{32}$ Missing data will be handled using multiple imputation methods assuming that data are missing at random. Specifically, we will use a combination of predictive mean matching and regression-based methods to impute missing data. A total of 100 data sets will be created to reduce sampling variability. A burn-in period of 500 iterations will be used. Imputation will be performed in Stata V.14.0 (StataCorp, College Station, Texas, USA).

\section{Monitoring}

\section{Adverse events}

AEs were defined as any untoward medical event or clinical investigation that a patient underwent even if it did not have a causal relation to the medical or surgical interventions. AEs were also defined as any unfavourable and unintended clinical manifestation or disease temporally associated with the surgical or medical treatment. Serious AEs (SAEs) are AEs that pose risk to life, result in hospital admission, increase hospital stays or may be debilitating or disabling. AEs and SAEs must be reported within 24 hours through detailed documentation and forwarded to the IRB. Follow-up of AEs/SAEs should be 
Table 3 Variable, measures and methods of analysis

\begin{tabular}{|c|c|c|c|}
\hline Variable/outcome & Hypothesis & Outcome measure & Methods of analysis \\
\hline \multicolumn{4}{|l|}{ Primary outcome } \\
\hline $\begin{array}{l}\text { Remission ( } \mathrm{uACR}<30 \mu \mathrm{g} \\
\text { of albumin/mg of creatinine) }\end{array}$ & $\begin{array}{l}\text { The proportion of remission is higher at } 12 \text {, } \\
24 \text { and } 60 \text { months in the RYGB+BMT arm } \\
\text { compared with the BMT-only arm. }\end{array}$ & Number of participants achieving remission & $\begin{array}{l}\text { Logistic regression (primary } \\
\text { analysis) and Cox proportional } \\
\text { hazards model (exploratory analysis) }\end{array}$ \\
\hline \multicolumn{4}{|l|}{ Secondary outcome } \\
\hline Glycaemic control & $\begin{array}{l}\text { Reduction is higher in the RYGB+BMT arm } \\
\text { compared with the BMT-only arm. }\end{array}$ & Fast glucose in mg/dL & $\begin{array}{l}\text { Mixed-effects generalised linear } \\
\text { models }\end{array}$ \\
\hline $\mathrm{HbA1c}$ & $\begin{array}{l}\text { Reduction is higher in the RYGB+BMT arm } \\
\text { compared to the BMT-only arm. }\end{array}$ & HbA1c levels (in \%) & $\begin{array}{l}\text { Mixed-effects generalised linear } \\
\text { models }\end{array}$ \\
\hline Blood pressure control & $\begin{array}{l}\text { The proportion of patients with blood } \\
\text { pressure control is higher in the RYGB } \\
\text { +BMT arm compared with the BMT-only } \\
\text { arm. }\end{array}$ & $\begin{array}{l}\text { Number of participants achieving systolic blood } \\
\text { pressure }<130 \mathrm{~mm} \mathrm{Hg} \text { and diastolic }<80 \mathrm{~mm} \mathrm{Hg}\end{array}$ & $\begin{array}{l}\text { Mixed-effects generalised linear } \\
\text { models }\end{array}$ \\
\hline Lipid control & $\begin{array}{l}\text { The proportion of patients with lipid control } \\
\text { is higher in the RYGB+BMT arm compared } \\
\text { with the BMT-only arm. }\end{array}$ & $\begin{array}{l}\text { Number of participants with } \mathrm{LDL}<100 \text { or }<70 \mathrm{mg} / \mathrm{dL} \\
\text { in patients with previous cardiovascular events; } \\
\mathrm{HDL}>50 \mathrm{mg} / \mathrm{dL} \text { and triglycerides }<150 \mathrm{mg} / \mathrm{dL}\end{array}$ & Logistic regression \\
\hline Retinopathy & Resolution of retinopathy & $\begin{array}{l}\text { Number of patients achieving resolution or } \\
\text { reduction in the degree of retinopathy and/or } \\
\text { macular oedema (severity scale) }\end{array}$ & Logistic regression \\
\hline Neuropathy & $\begin{array}{l}\text { New development or worsening of } \\
\text { neuropathy }\end{array}$ & $\begin{array}{l}\text { Number of patients with new or worsening of } \\
\text { neuropathy }\end{array}$ & Logistic regression \\
\hline Medical treatment & Reduction of medication for T2DM & $\begin{array}{l}\text { Number of medications necessary for targeting } \\
\text { euglycaemia }\end{array}$ & Linear regression \\
\hline Hepatic fibrosis & Improvement of fibrosis & Reduction of hepatic elastographic resistance & Logistic regression \\
\hline Voiding dysfunction & Improvement of voiding dysfunction & $\begin{array}{l}\text { Reduction in the degree of voiding dysfunction } \\
\text { symptoms }\end{array}$ & Logistic regression \\
\hline Quality of life (SF-36) & $\begin{array}{l}\text { Quality of life is higher in the RYGB+BMT } \\
\text { arm compared with the BMT-only arm. }\end{array}$ & Quality of life questionnaire & $\begin{array}{l}\text { Mixed-effects generalised linear } \\
\text { models }\end{array}$ \\
\hline \multicolumn{4}{|c|}{ Clinical and sociodemographic variables } \\
\hline Age & There is no difference between the RYGB & Years & Student's t-test \\
\hline $\mathrm{BMI}$ & +BMT arm compared with the BMT-only & $\mathrm{kg} / \mathrm{m}^{2}$ & Student's t-test \\
\hline Weight & arm at baseline. & $\mathrm{kg}$ & Student's t-test \\
\hline Gender & & $1=$ male, $0=$ female & Fisher's exact test \\
\hline Waist circumference & & $\mathrm{cm}$ & Student's t-test \\
\hline Urinary albumin & & $\mathrm{g} / \mathrm{dL}$ & Student's t-test \\
\hline Creatinine & & $\mathrm{mg} / \mathrm{dL}$ & Student's t-test \\
\hline Fasting blood glucose & & $\mathrm{mg} / \mathrm{dL}$ & Student's t-test \\
\hline Total, HDL and LDL cholesterol & & $\mathrm{mg} / \mathrm{dL}$ & Student's t-test \\
\hline Triglycerides & & $\mathrm{mg} / \mathrm{dL}$ & Student's t-test \\
\hline $\begin{array}{l}\text { Diastolic and systolic blood } \\
\text { pressure }\end{array}$ & & $\mathrm{mm} \mathrm{Hg}$ & Student's t-test \\
\hline
\end{tabular}

Survey; T2DM, type 2 diabetes mellitus; uACR, urine albumin-to-creatinine ratio. 
continued until resolution or stabilisation of the patients.

\section{Auditing}

Auditing will be carried out throughout the duration of the study by a dedicated monitor. It will include key indicators and will be carried out in all source documents/ participants. These key indicators are informed consent form (ICF) and process, eligibility criteria, enrolment, allocation of study groups, scheduled and missed tests and procedures, policies to protect participants, concomitant and prohibited medications, dispensing medication procedures, identification and reporting of AEs and SAEs, deviation report, regulatory documents and communication with local IRB, following International Conference on Harmonisation-Good Clinical Practice (ICH-GCP) and regulatory agency guidelines.

\section{Ethics and dissemination}

Research ethics approval

Protocol, ICF and recruitment materials were reviewed and approved by our local IRB. The initial approval was received on 25 February 2013 and since then they have been notified of the progress of the study on a regular basis.

\section{Protocol amendments}

All changes needed after the initial IRB approval will be submitted to the IRB for approval. Amendment to the clinical protocol ought to be implemented after a formal IRB approval and an updated informed consent signed by the patients and the investigators.

Protocols amendments/ICF changes were submitted to the IRB and approved before implementation. The history of changes is available and can be tracked by version and date changes.

\section{Consent}

Patients identified as possible participants received general information about the study from an investigator (medical doctor). Then they received the ICF and were given an opportunity to read and discuss with their relatives/friends. Then a formal discussion was performed between the investigator and the patient. During this process, the patient had the opportunity to ask questions and clarify all doubts. At the end, the patient who expressed willingness to make part of the study signed the ICF (as well as the investigator) and then became a study participant. Assent form and ancillary studies consent were not necessary for this study.

\section{Confidentiality}

All medical information derived from the study is confidential, and no third party disclosure was allowed. Source data/information will be handled by the designated personnel, and the information will be stored in password-protected computers and in coded patient notes to protect confidentiality.
Declaration of interests

The lead author (RVC) has received an honorarium as a member of the Speaker's panel of Johnson \& Johnson.

\section{Study sponsorship and access to data}

Data will be available for authorised investigators only. Third parties may have access to data with express written permission from the lead investigator (RVC). However, sponsors will not participate in data analysis nor will have access to data (either in full or in part).

\section{Ancillary and post-trial care}

The Oswaldo Cruz German Hospital has an insurance policy (specific for the MOMS protocol) to cover nonnegligent harm associated with the protocol, which covers additional healthcare, compensation or damages whether awarded voluntarily by the MOMS study or by claims pursued through the courts.

\section{Dissemination policy}

After the publication of the trial protocol, the investigators plan to publish all the listed end points, as this RCT is the first trial on BMT combined with metabolic surgery versus the best medical care without surgery for patients with T2DM with a BMI below $35 \mathrm{~kg} / \mathrm{m}^{2}$. The results of this trial will be published in peer-reviewed scientific journals and presented at major conferences, regardless of the magnitude or direction of the observed effect.

\section{Trial organisation and management}

The study investigators were responsible for completing all pertinent information using the clinical report forms, the accuracy of data and maintaining the confidentiality of patients' data. Only the investigators had access to the final data set. All documentation will be kept readily available for 5 years after the study termination in case it had to be monitored, audited or inspected by the sponsor or regulatory authorities.

Author affiliations

${ }^{1}$ The Center for Obesity and Diabetes, Oswaldo Cruz German Hospital, São Paulo, Brazil

${ }^{2}$ Health Technology Assessment Unit, Oswaldo Cruz German Hospital, São Paulo, Brazil

${ }^{3}$ Health Research Unit, Oswaldo Cruz German Hospital, São Paulo, Brazil

${ }^{4}$ Research Institute Hcor, Heart Hospital, São Paulo, Brazil

${ }^{5}$ Diabetes Complication Research Centre, UCD Conway Institute, School of Medicine and Medical Science, University College Dublin, Dublin, Ireland

Acknowledgements The authors would like to thank the staff of the Health Research Unit, Oswaldo Cruz German Hospital for the full assistance for the MOMS trial.

Contributors RVC, TVP, CMA, CIR and CMA conceived and designed the study and participated in logistical planning of the study, and were involved in the drafting of the article. TVP provided the statistical support for the sample size estimates and the design of the statistical analysis. TBZP and CEP were involved in the screening and randomisation process and are involved in the patient's follow-up. RVC, CAS, PPdPC, JLLC and FNQP performed all operations. 
Funding The study is supported by a research grant from Johnson \& Johnson Medical Brazil and Oswaldo Cruz German Hospital.

Competing interests None declared.

Ethics approval Local Institutional Review Board (IRB; Ethical Research Committee from Oswaldo Cruz German Hospital—\#201681).

Provenance and peer review Not commissioned; externally peer reviewed.

Data sharing statement The authors shall make data available to the scientific community with as few restrictions as feasible, ensuring anonymisation, while retaining exclusive use until the publication of major outputs.

Open Access This is an Open Access article distributed in accordance with the Creative Commons Attribution Non Commercial (CC BY-NC 4.0) license, which permits others to distribute, remix, adapt, build upon this work noncommercially, and license their derivative works on different terms, provided the original work is properly cited and the use is non-commercial. See: http:// creativecommons.org/licenses/by-nc/4.0/

\section{REFERENCES}

1. Schauer PR, Bhatt DL, Kirwan JP, et al. Bariatric surgery versus intensive medical therapy for diabetes-3-year outcomes. $N$ Engl J Med 2014;370:2002-13.

2. Schauer PR, Kashyap SR, Wolski K, et al. Bariatric surgery versus intensive medical therapy in obese patients with diabetes. $N$ Engl J Med 2012;366:1567-76.

3. Ikramuddin S, Korner J, Lee W-J, et al. Roux-en-Y gastric bypass vs intensive medical management for the control of type 2 diabetes, hypertension, and hyperlipidemia: the diabetes surgery study randomized clinical trial Roux-en-Y gastric bypass and diabetes. JAMA 2013;309:2240-9.

4. Ikramuddin S, Billington CJ, Lee WJ, et al. Roux-en-Y gastric bypass for diabetes (the Diabetes Surgery Study): 2-year outcomes of a 5-year, randomised, controlled trial. Lancet Diabetes Endocrinol 2015;3:413-22.

5. Mingrone G, Panunzi S, De Gaetano A, et al. Bariatric-metabolic surgery versus conventional medical treatment in obese patients with type 2 diabetes: 5 year follow-up of an open-label, single-centre randomised controlled trial. Lancet 2015;386:964-73.

6. Mingrone G, Panunzi S, De Gaetano A, et al. Bariatric surgery versus conventional medical therapy for type 2 diabetes. $N$ Engl J Med 2012;366:1577-85.

7. Gloy VL, Briel M, Bhatt DL, et al. Bariatric surgery versus non-surgical treatment for obesity: a systematic review and meta-analysis of randomised controlled trials. BMJ 2013;347:f5934.

8. Sjöholm K, Anveden Å, Peltonen M, et al. Evaluation of current eligibility criteria for bariatric surgery: diabetes prevention and risk factor changes in the Swedish Obese Subjects (SOS) study. Diabetes Care 2013;36:1335-40.

9. Sjöström L, Peltonen M, Jacobson P, et al. Association of bariatric surgery with long-term remission of type 2 diabetes and with microvascular and macrovascular complications. JAMA 2014;311:2297.

10. Ferrannini E, Mingrone G. Impact of different bariatric surgical procedures on insulin action and cell beta-cell function in type 2 diabetes. Diabetes Care 2009;32:514-20.
11. Sjöström L, Peltonen M, Jacobson $\mathrm{P}$, et al. Bariatric surgery and long-term cardiovascular events. JAMA 2012;307:56-65.

12. Romeo S, Maglio C, Burza MA, et al. Cardiovascular events after bariatric surgery in obese subjects with type 2 diabetes. Diabetes Care 2012;35:2613-17.

13. Adams TD, Gress RE, Smith SC, et al. Long-term mortality after gastric bypass surgery. N Engl J Med 2007;357:753-61.

14. Adams TD, Davidson LE, Litwin SE, et al. Health benefits of gastric bypass surgery after 6 years. JAMA 2012;308:1122-31.

15. Adams TD, Pendleton RC, Strong MB, et al. Health outcomes of gastric bypass patients compared to nonsurgical, nonintervened severely obese. Obesity (Silver Spring) 2010;18:121-30.

16. Rubino F, Amiel SA. Is the gut the "Sweet Spot" for the treatment of diabetes? Diabetes 2014;63:2225-8.

17. Pories WJ, Dohm LG, Mansfield CJ. Beyond the BMI: the search for better guidelines for bariatric surgery. Obesity (Silver Spring) 2010;18:865-71.

18. le Roux CW, Aylwin SJB, Batterham RL, et al. Gut hormone profiles following bariatric surgery favor an anorectic state, facilitate weight loss, and improve metabolic parameters. Ann Surg 2006;243:108.

19. Cummings DE, Cohen RV. Beyond BMI: the need for new guidelines governing the use of bariatric and metabolic surgery. Lancet Diabetes Endocrinol 2014;2:175-81.

20. Cohen R. Bariatric surgery: time to move beyond clinical outcomes. Lancet Diabetes Endocrinol 2015;3:829-31.

21. Sharma AM, Kushner RF. A proposed clinical staging system for obesity. Int J Obes 2009;33:289-95.

22. DeFronzo RA, Ferrannini E. Insulin resistance: a multifaceted syndrome responsible for NIDDM, obesity, hypertension, dyslipidemia, and atherosclerotic cardiovascular disease. Diabetes Care 1991:14:173-94.

23. Knowler WC, Fowler SE, Hamman RF, Diabetes Prevention Program Research Group. 10-year follow-up of diabetes incidence and weight loss in the Diabetes Prevention Program Outcomes Study. Lancet 2009;374:1677-86.

24. American Diabetes Association. Standards of medical care in diabetes--2013. Diabetes Care 2013;36(Suppl 1):S11-66.

25. Afkarian M, Sachs MC, Kestenbaum B, et al. Kidney disease and increased mortality risk in type 2 diabetes. J Am Soc Nephrol 2013;24:302-8

26. Gallagher H, Suckling RJ. Diabetic nephropathy - where are we on the journey from pathophysiology to treatment? Diabetes Obes Metab 2016;18:641-7.

27. Chen Y, Corsino L, Shantavasinkul PC, et al. Gastric bypass surgery leads to long-term remission or improvement of type 2 diabetes and significant decrease of microvascular and macrovascular complications. Ann Surg 2016;263:1138-42.

28. Upala S, Wijarnpreecha $\mathrm{K}$, Congrete $\mathrm{S}$, et al. Bariatric surgery reduces urinary albumin excretion in diabetic nephropathy-a systematic review and meta-analysis. Surg Obes Relat Dis 2016;12:1037-44.

29. Schauer PR, Burguera B, Ikramuddin S, et al. Effect of laparoscopic Roux-en Y gastric bypass on type 2 diabetes mellitus. Ann Surg 2003;238:467-84

30. Cohen RV, Pinheiro JC, Schiavon CA, et al. Effects of gastric bypass surgery in patients with type 2 diabetes and only mild obesity. Diabetes Care 2012;35:1420-8.

31. Cummings DE, Cohen RV. Bariatric/metabolic surgery to treat type 2 diabetes in patients with a $\mathrm{BMl}<35 \mathrm{~kg} / \mathrm{m}$ 2. Diabetes Care 2016;39:924-33.

32. White IR, Horton NJ, Carpenter J, et al. Strategy for intention to treat analysis in randomised trials with missing outcome data. BMJ 2011;342:d40 


\section{Correction}

Cohen RV, Pereira TV, Aboud CM on behalf of MOMS Study Investigators, et al. Microvascular Outcomes after Metabolic Surgery (MOMS) in patients with type 2 diabetes mellitus and class I obesity: rationale and design for a randomised controlled trial. BMJ Open 2017;7:e013574. doi: 10.1136/bmjopen-2016-013574

The author Carel le Roux should be listed as Carel W le Roux. His ORCID number is 0000000155215445 .

Open Access This is an Open Access article distributed in accordance with the Creative Commons Attribution Non Commercial (CC BY-NC 4.0) license, which permits others to distribute, remix, adapt, build upon this work non-commercially, and license their derivative works on different terms, provided the original work is properly cited and the use is non-commercial. See: http://creativecommons.org/licenses/by-nc/4.0/

BMJ Open 2017;7:e013574corr1. doi:10.1136/bmjopen-2016-013574corr1 